\title{
ANÁLISE DO ENSINO REMOTO EMERGENCIAL NUMA MICRORREGIÃO DO INTERIOR PAULISTA
}

\author{
ANÁLISIS DE LA ENSEÑANZA REMOTA DE EMERGENCIA EN UNA \\ MICROREGION EN EL INTERIOR DE SÃO PAULO
}

\author{
ANALYSIS OF EMERGENCY REMOTE TEACHING IN A MICROREGION IN THE \\ COUNTRYSIDE OF SÃO PAULO
}

\author{
Evelin Louise Pavan Ribeiro TEBALDI ${ }^{1}$ \\ Sebastião de Souza LEMES $^{2}$
}

RESUMO: Este artigo é parte de uma pesquisa de doutorado que tem por objeto de estudos, o planejamento das atividades escolares para o período de ensino remoto emergencial implementado em 2020, em decorrência da pandemia da Covid-19, no âmbito das redes municipais de ensino dos municípios de uma microrregião do interior paulista. O objetivo da pesquisa é compreender como esse momento foi pensado, identificando, descrevendo e analisando estratégias de ensino remoto, dificuldades, ações bem-sucedidas e inovações que essa situação propiciou a esses municípios. Para tanto, foi realizada uma pesquisa bibliográfica e documental acerca do ensino remoto, além de uma pesquisa de campo com as equipes pedagógicas que o planejaram em seus municípios. O estudo aqui apresentado destaca a análise descritiva dessa pesquisa, que se mostra relevante pela necessidade de registro das experiências vivenciadas nesse momento, as quais podem, se bem-sucedidas, ser aproveitadas no pós-pandemia para melhorar a qualidade da educação.

PALAVRAS-CHAVE: Política educacional. Ensino remoto. Estratégias de ensino.

RESUMEN: Este artículo forma parte de una investigación de doctorado cuyo objeto de estudio es la planificación de las actividades escolares para el período de enseñanza remota de emergencia implementado en 2020, como consecuencia de la pandemia Covid-19, en el ámbito de las redes de educación municipal en los municipios de una microrregión del interior de São Paulo. El objetivo de la investigación es comprender cómo se pensó este momento, identificando, describiendo y analizando las estrategias de enseñanza a distancia, las dificultades, las acciones exitosas y las innovaciones que esta situación aportó a estos municipios. Para ello, se realizó una investigación bibliográfica y documental sobre la enseñanza a distancia, además de una investigación de campo con los equipos pedagógicos que la planificaron en sus municipios. El estudio aquí presentado destaca el análisis descriptivo de esta investigación, el cual es relevante por la necesidad de registrar las

\footnotetext{
1 Universidade Estadual Paulista (UNESP), Araraquara - SP - Brasil. Doutoranda no Programa de PósGraduação em Educação Escolar. Bolsista CAPES. ORCID: https://orcid.org/0000-0002-6189-2482. E-mail: evelintebaldi@gmail.com

${ }^{2}$ Universidade Estadual Paulista (UNESP), Araraquara - SP - Brasil. Professor do Departamento de Educação e Coordenador do Programa de Pós-Graduação em Educação Escolar. Editor. ORCID: https://orcid.org/00000002-0750-9294. E-mail: sebastiao.lemes@unesp.br
} 
experiencias vividas en ese momento, las cuales, se exitosass, pueden ser utilizadas en la pospandémica para mejorar la calidad de la educación.

PALABRAS CLAVE: Política educativa. Enseñanza remota. Estrategías de enseñanza.

ABSTRACT: This article is part of a doctoral research whose object of study is the planning of school activities for the period of emergency remote education implemented in 2020, as a result of the Covid-19 pandemic, within the scope of municipal education systems of a microregion of the countryside of São Paulo. The objective of the research is to understand how this moment was thought, identifying, describing and analyzing remote teaching strategies, difficulties, successful actions and innovations that this situation provided to these counties. Therefore, a bibliographical and documental research on remote teaching was carried out, in addition to field research with the pedagogical teams that planned it in their counties. The study presented here highlights the descriptive analysis of this research, which is relevant due to the need to record the experiences lived at that time, which, if successful, can be used in the post-pandemic to improve the quality of education.

KEYWORDS: Educational policy. Remote teaching. Teaching strategies.

\section{Introdução}

Os anos de 2020 e 2021 sofreram no mundo todo o impacto da pandemia da Covid-19. Para evitar a propagação da pandemia, os governos dos estados e dos municípios brasileiros implementaram medidas de distanciamento social, entre as primeiras está a suspensão das atividades escolares presenciais.

Entendendo a importância da educação institucionalizada para o processo de ensino e de aprendizagem dos alunos, estados e municípios se mobilizaram para dar prosseguimento às atividades escolares sob a influência das experiências da Educação a Distância (EAD), das Tecnologias da Informação e da Comunicação (TIC) e das Tecnologias Digitais de Informação e Comunicação (TDIC). As vivências implementadas são denominadas por ensino remoto por não serem consideradas $\mathrm{EAD}$, já que não utilizam e nem são concebidas dentro dessa metodologia específica (CRAIG, 2020). O adjetivo emergencial foi adicionado devido ao caráter em que essa medida foi implementada e em referência à licença concedida pela Lei de Diretrizes e Bases Nacional - LDB nº 9.394 de 1996 (BRASIL, 1996) para o uso de ensino a distância na educação básica.

Segundo pesquisa realizada pelo Centro de Inovação para a Educação Brasileira (CIEB, 2020), que analisou estratégias de ensino remoto utilizadas por Secretarias de Educação brasileiras em março de 2020, em comparação com as Secretarias Estaduais de Educação (SEE), as Secretarias Municipais de Educação (SME) não estavam preparada para 
desenvolver atividades de ensino remoto. Essa falta de preparo ocorre pela ausência de experiência com o uso das TIC e TDIC em larga escala, de recursos, de formação de pessoal e de conectividade dos estudantes às ferramentas disponibilizadas.

Procurando compreender se os municípios paulistas estavam preparados para o Ensino Remoto Emergencial (ERE), propusemos uma pesquisa junto às Secretarias e aos Departamentos Municipais de Educação (DME) dos municípios de uma microrregião do interior de São Paulo, situada na mesorregião de Campinas.

A microrregião estudada estimava, em 2020, uma população de 272 mil habitantes dividida em dois municípios de grande porte, um de pequeno porte II e um de pequeno porte I (IBGE, 2021). Esses municípios foram enquadrados nessa microrregião por apresentarem proximidade territorial e dependência intermunicipal quanto às atividades comerciais, aos bens e aos serviços públicos e privados para a satisfação das necessidades da população (IBGE, 2017). São municípios com considerável mobilidade entre a população para questões de trabalho, saúde, educação, consumo, entre outros.

No que se refere à educação dessa microrregião, a taxa média de escolarização para o ensino fundamental no Censo 2010 era de 97,8\% e a média do Índice de Desenvolvimento da Educação Básica (IDEB), de 2019, para os anos iniciais do ensino fundamental era de 6,9 (INEP, 2021). Em 2020, o Censo Escolar registrou, no que diz respeito às redes municipais de ensino, 15.641 matrículas na educação infantil distribuídas em 127 escolas, e 11.805 matrículas nos anos iniciais do ensino fundamental distribuídas em 43 escolas. Ao todo, contava-se 1.982 professores locados nessas redes de ensino (IBGE, 2021).

Contemplando a realidade local, nosso objeto de estudo é o planejamento do ERE pelas equipes pedagógicas das redes municipais de ensino desta microrregião, durante o período de suspensão de aulas presenciais ocasionada pela Covid-19. O objetivo geral é compreender como esse momento foi planejado pelas Secretarias e Departamentos Municipais de Educação. Seguido dos objetivos específicos: i) identificar, descrever e analisar, por meio das manifestações dessas equipes pedagógicas, as estratégias de ensino utilizadas para a implementação do ERE; ii) levantar as dificuldades e as ações bem-sucedidas percebidas durante esse processo e; iii) revelar as inovações que essa situação trouxe para esses locais. Nesse artigo, dada a circunstância do momento atual, optou-se por apresentar um extrato analítico do estudo hora em andamento.

Destarte, esta é uma pesquisa qualitativa, de caráter descritivo, cuja metodologia envolve uma revisão bibliográfica, uma pesquisa documental e uma pesquisa de campo com entrevistas junto às equipes pedagógicas dos municípios dessa microrregião. 
Nossa pesquisa mostra, por meio das manifestações dos entrevistados, que, como apontado pelo CIEB (2020), os municípios estudados não tinham experiência nem estavam preparados para o ERE ou para o uso da tecnologia em larga escala. Contudo, essa implementação parece ter acelerado um processo de transformação, por meio da integração das TIC e TDIC, que, aos olhos dos entrevistados (e nossos), tem o potencial para trazer o começo de um novo tempo para a educação.

\section{Educação a distância, ensino presencial e ensino remoto}

Para distinguirmos melhor os termos Educação a Distância (EAD), ensino remoto e ensino presencial, propomos uma breve diferenciação teórica, para fins didáticos, tendo em vista a legislação e estudiosos da área. Começaremos pelo termo EAD, levando em vista a legislação que regulamenta a modalidade a partir do Decreto Federal $n^{\circ}$ 9.057, que em seu artigo $1^{\circ}$ (BRASIL, 2017, p. 1),

Considera educação a distância a modalidade educacional na qual a mediação didático-pedagógica nos processos de ensino e aprendizagem ocorra com a utilização de meios e tecnologias de informação e comunicação, com pessoal qualificado, com políticas de acesso, com acompanhamento e avaliação compatíveis, entre outros, e desenvolva atividades educativas por estudantes e profissionais da educação que estejam em lugares e tempos diversos.

O conceito de EAD vai além de um processo de ensino e aprendizagem entre indivíduos distantes física e temporalmente mediado por tecnologias, mas envolve estratégias que, em inovação, superam as do ensino presencial, definido comumente por metodologias e práticas de ensino e avaliação mais tradicionais e hierarquizados.

Como apontam Machado, Czarnesk e Domingues (2015, p. 106-107):

O ensino presencial para fins deste estudo é entendido como sinônimo de ensino tradicional. Mizukami (1986) apresenta algumas características da abordagem tradicional do processo de ensino-aprendizagem: a) educação: entendida como um processo amplo, ou seja, instrução que se caracteriza pela transmissão de conhecimento e restrita à ação da escola; b) processo de ensino-aprendizagem com ênfase às situações de sala de aula, em que os alunos são ensinados pelo professor; c) relação vertical entre professoraluno, em que o professor detém o processo decisório; d) metodologia de desenvolvimento das aulas com uso frequente do método expositivo, concebendo ao magistério uma arte centrada no professor. A autora explica que nessa metodologia de aula está implícito o relacionamento professor versus aluno, em que o professor é o agente e o aluno é o ouvinte; e, por fim, e) avaliação realizada visando à exatidão da reprodução do conteúdo comunicado em sala de aula. 
No geral, os alunos do ensino presencial têm uma posição mais passiva do que os da EAD, que proporciona ferramentas de participação coletiva para suprir a interação presencial, de pesquisa e de produção de conteúdos e atividades que envolvem a autonomia e o protagonismo do aluno, trazendo mais dinamismo às práticas de ensino.

Quanto ao dinamismo que a tecnologia pode agregar à educação, Nicola, Paralo e Lemes apontam que (2021, p. 348),

A educação precisa de uma nova roupagem, novos horizontes e possibilidades de estimular o entusiasmo tanto do professor quanto do aluno. A tecnologia vem para trazer um estímulo diferente do que se tem no ensino tradicional. A aplicação inteligente do computador facilita a passagem do modelo mecanicista para o sociointerativista.

Além da distinção entre EAD e ensino presencial é preciso definir o que consideramos aqui por ERE. O ERE diferencia-se da EAD pela forma de pensar a frequência e em decorrência deste último desfrutar de metodologia e ferramentas próprias e o primeiro adaptar o ensino presencial ao remoto, utilizando algumas ferramentas e estratégias da EAD, TIC e TDIC, nem sempre de forma estruturada.

O ensino remoto é um formato de escolarização mediado por tecnologia, mantidas as condições de distanciamento professor e aluno. [...] Embora esteja diretamente relacionado ao uso de tecnologia digital, ensinar remotamente não é sinônimo de ensinar a distância, considerando esta última uma modalidade que tem uma concepção teórico-metodológica própria e é desenvolvida em um ambiente virtual de aprendizagem, com material didático-pedagógico específico e apoio de tutores (GARCIA et al., 2020, p. $5)$.

Feitas as devidas distinções, é preciso entender que o ERE está mais próximo do ensino presencial do que da EAD em termos de metodologia e estratégias de ensino. Da EAD o ERE tem, no geral, emprestado apenas os recursos tecnológicos e a forma de computar frequência, mantendo práticas de aulas expositivas e atividades orientadas para posterior entrega e correção, as quais são tradicionais no ensino presencial.

Ciente das críticas que a transposição do ensino presencial para o remoto tem tido, mas dada a sua materialidade no Estado de São Paulo e a urgência de se pensar estratégias para a não interrupção das aulas, destacamos o posicionamento favorável ao ERE da organização civil Todos pela Educação (2020, p. 3, grifos do documento), 
Frente a um cenário sem precedentes [...] busca-se evitar [...] uma leitura "fria" das pesquisas sobre ensino a distância, que, em geral, se concentram em comparar "aulas a distância" com "aula presenciais" (enquanto, no cenário atual, a questão é, fundamentalmente, uma discussão entre "aulas a distância" e "não realização de aulas"). [...] a escolha do poder público em nada fazer, sob o argumento de que não é possível chegar em todos, tende a exacerbar as desigualdades resultantes da situação de emergência.

Embora toda a discussão sobre a qualidade duvidosa do ERE, implementado de forma paliativa, temporária, ao mesmo tempo em que é estruturado, o Todos pela Educação defende que não podemos deixar de fazer o processo educativo chegar aos alunos. Esse tem sido um discurso corrente dos entrevistados dessa pesquisa.

\section{A implantação do Ensino Remoto Emergencial}

Pela legislação brasileira, a educação básica segue a normativa prescrita pela LDB $\mathrm{n}^{\text {o }}$ 9.394/1996 (BRASIL, 1996). Com relação à frequência ao ensino regular na educação básica, o artigo $5^{\circ}$ da LDB $n^{\circ}$ 9.394/1996 (BRASIL, 1996) prescreve que seu zelo é responsabilidade do Estado e dos pais, no entanto, só esclarece o tipo de frequência prevista para o ensino fundamental: parágrafo $4^{\circ}$, artigo 32: "será presencial, sendo o ensino a distância utilizado como complementação da aprendizagem ou em situações emergenciais" (BRASIL, 1996).

O artigo 24 da LDB n 9.394/1996 (BRASIL, 1996) regulamenta a frequência escolar no ensino fundamental e médio e o artigo 31, na educação infantil; ambos propõem uma carga horária mínima de 800 horas letivas e um número mínimo de 200 dias letivos anuais, sendo o controle realizado pela instituição escolar. Durante a pandemia da Covid-19 em 2020, a Lei Federal $n^{\circ}$ 14.040/2020 (BRASIL, 2020), dispensou o cumprimento dos 200 dias letivos na educação básica e das 800 horas letivas na educação infantil.

Embora, na história da instituição escolar a frequência tenha sido fisicamente presencial, com a ampliação da EAD no século XXI, algumas modalidades e níveis de ensino têm sido pensados no formato a distância, como o ensino superior, o ensino técnico e tecnológico, a Educação de Jovens e Adultos, entre outros.

No que toca à educação básica, o Decreto Federal no 9.057/2017, que regulamenta o artigo 80 da LDB n 9.394/1996 (BRASIL, 1996), regula a "oferta de cursos na modalidade a distância na Educação Básica" e coloca em seu artigo $8^{\circ}$ que "compete às autoridades dos sistemas de ensino estaduais, municipais e distrital, no âmbito da unidade federativa, autorizar os cursos e o funcionamento de instituições de educação na modalidade a distância”, nos 
termos da lei (BRASIL, 2017). Com base nesse Decreto, estados e municípios aprovaram a implementação do ERE em seus sistemas de ensino.

No Estado de São Paulo, a Deliberação do Conselho Estadual de Educação (CEE) $n^{\circ}$ 177/2020 (SÃO PAULO, 2020e) fixou premissas para a reorganização dos calendários escolares de 2020. A Deliberação reconhece a autonomia das instituições escolares para essa reorganização, desde que assegurem os objetivos educacionais do ano letivo, aprovem e registrem as alterações por meio dos respectivos órgãos reguladores. Entre essas premissas estão a utilização de todos os meios possíveis para minimizar as perdas dos alunos com a suspensão das aulas presenciais, a redução dos 200 dias letivos, mas não das 800 horas letivas (excetuando o caso da educação infantil), a utilização de recursos das TIC e TDIC, a realização de atividades fora da escola, o respeito às especificidades e à faixa etária dos alunos, a reorganização dos períodos de férias, recesso, provas, exames, reuniões e demais atividades, a previsão de períodos de reposição de aulas e a definição das atividades para esses períodos (SÃO PAULO, 2020e).

Com base nessa Deliberação, os municípios participantes dessa pesquisa reorganizaram seus calendários de forma a cumprir as 800 horas letivas de 2020. A reorganização do calendário foi o primeiro passo para o planejamento do ERE, pois ele permitiu antecipar períodos de recesso e férias escolares, dando tempo às redes municipais de ensino para se organizarem e se estruturarem.

Outras resoluções estaduais que ajudaram a organização do ERE foram: a Resolução Seduc-45/2020 (SÃO PAULO, 2020c), que dispôs sobre o planejamento, a realização e o registro de atividades educacionais não presenciais para as instituições escolares paulistas; a Resolução Seduc-46/2020 (SÃO PAULO, 2020b), que estabeleceu um protocolo de entrega de materiais pedagógicos aos alunos; e a Resolução Seduc-48/2020 (SÃO PAULO, 2020a), que definiu as atividades de natureza essencial prestadas pelas Secretarias de Educação. Com base nessas normativas, entre outras, os sistemas de ensino municipais paulistas adequaram seus planos de ensino de forma a atender à regulação estadual no que se refere ao planejamento e a implementação do ERE em 2020.

\section{Metodologia}

A metodologia dessa pesquisa qualitativa, de caráter descritivo, envolveu uma revisão bibliográfica sobre o contexto de implantação do ERE, uma pesquisa documental sobre a 
legislação que propiciou a implementação desse sistema e uma pesquisa de campo nos municípios selecionados para o estudo.

Na pesquisa de campo, realizamos entrevistas online com os profissionais das equipes pedagógicas encarregadas desse planejamento em cada um dos municípios da microrregião selecionada, por intermédio da ferramenta Google Meet, as quais foram gravadas e, posteriormente, transcritas para a categorização e análise de dados.

As entrevistas ocorreram com a autorização dos Secretários e Diretores Municipais de Educação, seguida do contato com os participantes das equipes pedagógicas dos municípios para identificação de voluntários, os quais assentiram com o Termo de Consentimento Livre e Esclarecido da pesquisa. Ao todo, foram entrevistados onze voluntários ou participantes.

As entrevistas seguiram um roteiro produzido previamente, flexível, no qual constavam perguntas sobre o processo de planejamento e implementação do ERE nos municípios da microrregião selecionada e que tinham como finalidade responder aos objetivos geral e específicos da pesquisa, descritos na Introdução desse artigo.

Para a análise de dados, baseamo-nos na Análise de Conteúdo de Bardin (2016), a qual sugere três fases para a organização de uma pesquisa: $1^{\text {a }}$ fase) pré-análise, na qual organizamos os dados da entrevista, fazendo as transcrições e uma pré-seleção de extratos de manifestações representativas que pudessem responder às nossas questões de pesquisa; $2^{\mathrm{a}}$ fase) exploração do material, na qual definimos as categorias de análise e as manifestações definitivas que pudessem melhor representá-las. As categorias definidas foram estratégias de ensino, dificuldades encontradas, ações bem-sucedidas e inovações para o ensino. Para cada categoria, delimitamos três subcategorias para discussão, em ordem de maior para menor recorrência. $\mathrm{Na} 3^{\mathrm{a}}$ fase, tratamento dos resultados, inferência e interpretação, iniciamos a análise descritiva dos dados.

\section{Análise de dados}

Esta etapa do artigo visa descrever os dados coletados nas entrevistas realizadas com as equipes pedagógicas das redes municipais de ensino de uma microrregião paulista. Nessas entrevistas foram realizadas perguntas sobre o processo de planejamento do ERE, para os anos iniciais do ensino fundamental e educação infantil, dos municípios pertencentes a essa microrregião. Essas perguntas tiveram como finalidade responder aos objetivos geral e específicos desse estudo. Estes últimos definiram nossas categorias de análise, abordadas a seguir: 1) estratégias de ensino; 2) dificuldades enfrentadas na implementação do ERE, 3) ações bem-sucedidas na implementação do ERE, e 4) inovações observadas com a implementação do ERE. 


\section{Características do planejamento do ERE numa microrregião paulista}

A implementação do ERE na microrregião paulista estudada não se deu de maneira uniforme. Entre os municípios participantes da pesquisa, temos um de pequeno porte I, um de pequeno porte II e dois de grande porte ${ }^{3}$. Consideramos destacar o fator porte municipal nesse estudo, por entender, por meio das manifestações dos entrevistados, que ele potencialmente teve um peso nas propostas de planejamento do ERE em dois sentidos: na centralização do planejamento inicial do ERE nas SME e na escolha da plataforma de ensino online como estratégia inicial para implementar o ERE.

Nos municípios de grande porte, o planejamento inicial do ERE ficou a cargo das equipes pedagógicas das SME. Nas manifestações dos entrevistados, distinguimos três argumentos para essa centralização: o fato de o fechamento emergencial das escolas ter acarretado a antecipação de férias e recessos dos professores, a urgência de se pensar uma estratégia uniforme para o atendimento da rede municipal como um todo e a necessidade se preparar os professores para a implementação do ERE.

Nos municípios de menor porte, o planejamento inicial do ERE foi coordenado pela equipe pedagógica das DME e pelos gestores das escolas, incluindo consulta aos professores. Esses locais, após os períodos de antecipação de férias e recessos, focaram no trabalho dos professores para as intervenções pedagógicas remotas com os alunos, a produção de roteiros de atividades e aulas e o plantão de dúvidas.

A antecipação de férias e recesso foi um procedimento oficial da rede estadual paulista de ensino, implementada pela Resolução Seduc-28 em março de 2020 (SÃO PAULO, 2020d), para propor medida de contenção à Covid-19 e obter tempo para o planejamento do ERE. Muitos municípios paulistas seguiram o cronograma da SEE integral ou parcialmente com o mesmo intuito. Esse foi o caso dos municípios de pequeno porte desse estudo.

Tanto as medidas de suspensão de aulas presenciais quanto seu prolongamento devido ao espalhamento da Covid-19 pegaram a comunidade escolar de surpresa. Na expectativa de alguns entrevistados, a suspensão de aulas presenciais seria temporária, assim como o ERE, tendo o retorno às aulas presenciais ainda em 2020. Como resultado do prolongamento da suspensão de aulas presenciais, os municípios tiveram que ajustar o planejamento inicial, pensado para um curto período de tempo, para todo o ano de 2020. Alguns municípios mantiveram as estratégias de ensino remoto com pequenas variações, enquanto outros as

${ }^{3}$ Os municípios brasileiros de pequeno porte têm até 50.000 habitantes, sendo subdivididos em pequeno porte I, com até 20.000 habitantes, e pequeno porte II, de 20.000 a 50.000 habitantes, os de médio porte de 50.000 a 100.000 habitantes, os de grande porte de 100.000 a 900.000 habitantes (BRASIL, 2004). 
modificaram ou complementaram significativamente. A principal alteração realizada foi a transferência da intervenção pedagógica com os alunos para os professores nos municípios em que isso ainda não ocorria.

Após o período inicial de implementação do ERE, todos os municípios da microrregião em questão propunham em seus planejamentos intervenções pedagógicas entre escola e aluno mediadas pelos professores de maneira que os processos de ensino pudessem ser mais próximos das características e necessidades do alunado.

As redes de apoio buscadas pelos municípios para alicerçar o planejamento do ERE foi outro fator de influência no planejamento. Os municípios de pequeno porte manifestaram mais reiteradamente ter buscado suporte nas orientações das Diretorias de Ensino do Estado de São Paulo (DE), da União dos Dirigentes Municipais de Educação (UNDIME), dos sistemas educacionais de editoras aos quais são vinculados, caso do município de pequeno porte I, e na troca de experiências com municípios de outras regiões, do que os de grande porte. No entanto, essa busca também sobreveio nas manifestações dos entrevistados dos municípios maiores.

Segundo alguns entrevistados, a UNDIME-SP (2021) teve considerável impacto na transmissão de orientações, informações e na formação dos profissionais das redes municipais de educação por meio de uma ampla oferta de videoconferências, webinars e discussões sobre o ERE durante a pandemia.

No que diz respeito às Diretorias de Ensino Estaduais, histórica e legalmente há uma relação de apoio e orientação destas para com as SME e DME oriunda do regime de colaboração constitucional entre estes entes federativos (artigo 211 da Constituição Federal de 1988, BRASIL, 1988). Além disso, a LDB nº 9.394/1996 (BRASIL, 1996), em seu artigo 10, coloca que é incumbência do estado e dos municípios, assegurar o ensino fundamental, o que destaca o papel do estado enquanto corresponsável por esse nível de ensino não apenas no que diz respeito ao seu oferecimento, mas à manutenção das instituições e à formação de profissionais. Nesse sentido, as orientações da Diretoria de Ensino da região influenciaram o planejamento do ERE nos municípios estudados, em especial nos de pequeno porte.

A seguir, abordaremos as categorias e subcategorias de análise desse estudo.

\section{1) Estratégias de ensino}

Para esta categoria de análise, consideramos por estratégia todo plano de ação(es) pedagógica(s) selecionado(s) para se estabelecer um processo de ensino e aprendizagem 
remoto entre o sistema de ensino e seus alunos, os quais podem abranger o uso de diferentes tecnologias, materiais didáticos, intervenções e ainda alterná-los.

Os municípios da microrregião estudada lançaram mão de uma série de estratégias de ensino para a não interrupção das atividades escolares. Entre as estratégias mais utilizadas para a disponibilização de materiais didáticos, roteiros de aulas, cronogramas de estudos, guias de orientações e intervenção pedagógica estão, conforme descrevemos a seguir:

a. distribuição de materiais impressos

A estratégia de ensino mais utilizada para a implementação do ERE foi a distribuição de materiais impressos. Todos os municípios se utilizaram dela. A justificativa para a implementação dessa estratégia recai sobre a imprescindibilidade de atingir todos os alunos, inclusive os que não têm acesso à internet. O município de pequeno porte II adotou-a como estratégia principal, não utilizando oficialmente ferramentas tecnológicas na intermediação do ERE. Mesmo os municípios que optaram por estratégias que exigiam a tecnologia como plano de ação principal utilizaram a distribuição de materiais impressos como um procedimento complementar e/ou concomitante para o contexto regular do ERE e para o atendimento dos alunos sem acesso à tecnologia. Entre os materiais impressos podemos listar os livros didáticos distribuídos pelo Programa Nacional do Livro Didático, as apostilas utilizadas pelo sistema de ensino e as atividades fotocopiadas produzidas pelos professores etc.

b. uso de plataforma de ensino online

No caso do uso de plataformas de ensino online, as SME dos municípios de grande porte utilizaram a plataforma Google for Education e suas ferramentas, como o Google Classroom. Em via de regra, o uso da plataforma com os alunos se restringiu à disponibilização de materiais pedagógicos para que estes pudessem cumprir os conteúdos de ensino produzidos e tutorados inicialmente pela SME. Assim que o planejamento e as intervenções pedagógicas foram transferidas para os professores, foi-lhes dada livre escolha para a gravação ou não de aulas, intervenções e orientações via Google Meet ou outro aplicativo a escolha, o que ocorreu por parte de alguns professores, mas não de forma generalizada ou mesmo sistematizada.

Os entrevistados dos municípios de pequeno porte declararam que a plataforma de ensino online não era a melhor opção para sua comunidade escolar. Entre as justificativas estão a questão orçamentária e o acesso precário dos alunos à internet. 
c. criação de grupos de salas de aula pelo WhatsApp ou WhatsApp Business

A criação de grupos de salas de aula pelo WhatsApp ou WhatsApp Business para a realização de intervenções docentes e disponibilização de materiais foi uma estratégia oficial em dois municípios, um de pequeno e outro de grande porte, sendo optativo nos outros dois municípios. Contudo, após a fase inicial de implementação do ERE, todos os municípios passaram a utilizá-lo para as intervenções pedagógicas realizadas entre docente/escola e aluno/família, mesmo que de forma não sistematizada.

Essa foi a ferramenta tecnológica mais utilizada pelos municípios dessa microrregião. A manifestação a seguir traz uma justificativa para o uso deste:

Participante I - "1) Porque muitas operadoras oferecem planos de dados infinitos para o WhatsApp. 2) Todas as famílias ou praticamente todas as familias têm WhatsApp e ela sabe mexer nisso, as crianças sabem mexer no aplicativo, ele é muito simples. [3] É um aplicativo que aceita todos os tipos de mídia: PDF, mpeg, MP4, áudio."

Segundo o CIEB (2020), “a maioria dos municípios entende que orientações por WhatsApp, envio de materiais digitais pelo professor e videoaulas gravadas e enviadas aos estudantes via redes sociais, são as estratégias mais adequadas à realidade da rede.” O envio de orientações via WhatsApp ficou em primeiro lugar entre as medidas tecnológicas que melhor se adequam ao contexto das redes municipais para o oferecimento do ERE. Essa pesquisa revelou que o fato de o WhatsApp ter se tornado um aplicativo básico para a comunicação no Brasil, tornou-o a ferramenta mais apropriada para a mediação escola-aluno na perspectiva dos municípios.

Todos os municípios utilizaram mais de uma das estratégias citadas, embora os municípios de grande porte tenham optado por utilizar a plataforma de ensino online no início da implementação do ERE, enquanto o de pequeno porte I utilizou o WhatsApp para as intervenções pedagógicas desde o início desse processo e o de pequeno porte II optou por utilizar, como estratégia principal, a disponibilização de materiais impressos.

Percebemos nas manifestações dos entrevistados que a utilização de várias estratégias concomitantemente tem como intenção disparar informações de diferentes formas a fim de alcançar ampla divulgação e atendimento integral dos alunos.

\section{2) Dificuldades enfrentadas para a implementação do ERE}

Alguns municípios enfrentaram problemas específicos na implementação do ERE, como ter grande parte do alunado na zona rural, caso do município de porte pequeno I, outros 
problemas, como as dificuldades de acesso à tecnologia, foram gerais. Nos ateremos, a seguir, aos problemas mais recorrentes na implementação do ERE.

a. falta de acesso de alunos e professores aos recursos tecnológicos selecionados

A impossibilidade de atingir todos os alunos da rede municipal de ensino pela falta de acesso à tecnologia foi a dificuldade mais destacada pelos entrevistados. Discernimos, nas manifestações, que essa preocupação apareceu mesmo antes da implementação do ERE e, nos municípios de pequeno porte, influenciou a decisão de não adotar uma plataforma de ensino online, mas estratégias mais próximas à realidade da comunidade escolar. Essa dificuldade também levou todos os municípios a optarem pela distribuição de materiais impressos aos alunos com o intuito de que o processo de escolarização pelo ERE chegasse a todos.

Participante $\boldsymbol{G}$ - "Nós fomos monitorando, né, a participação dessas crianças. E aí você vê que tinha muitos problemas. Tem família que tem cinco crianças e um celular, né, e cada criança numa sala, não tem internet [...]."

Alguns professores também necessitaram de suporte tecnológico para realizar o planejamento e as intervenções pedagógicas com os alunos. Para suprir essa demanda, a maior parte dos municípios ofereceu os recursos disponíveis nas instituições escolares para que os professores pudessem cumprir essas atividades. Algumas instituições escolares disponibilizaram notebooks para serem usados em sistema home office.

Embora, no geral, os participantes entrevistados tenham apontado a preocupação dos municípios em disponibilizar aos professores os recursos tecnológicos necessários, um dos entrevistados alertou que, no caso do seu município, a capacidade das redes é limitada e, caso fosse preciso oferecer recursos institucionais a todos os professores, diretores e coordenadores, haveria, provavelmente, problemas, principalmente no que se refere à velocidade da conexão da internet. Essa é a realidade no uso das TIC no Brasil.

b. falta de fluência digital por parte dos professores

A falta de fluência digital dos alunos-famílias, mas principalmente dos professores foi outro fator apontado nas entrevistas como gerador de dificuldades. Grande parte dos professores não estava familiarizada com os recursos tecnológicos selecionados para implementar o ERE, como plataformas de ensino online, gravação de videoaulas e áudios, aulas online, disponibilização de postagens, encaminhamento de atividades via plataforma etc. 
Participante $\boldsymbol{K}$ - "O problema maior foi, éh, gravar o vídeo, mostrar o rosto, né. Então isso daí, elas ficaram meio que [...] muitas com dificuldade de como gravar. [...] Eu tive professor com dificuldade de digitar até o próprio cronograma. Então dai o que serviu pra gente observar? Que os professores precisam de mais formação na área tecnológica."

Segundo Tarouco (2018, p. 33), "no contexto atual, da chamada sociedade da informação, a alfabetização digital é um dos pontos mais críticos no processo de inclusão digital. Ela está relacionada à aquisição de habilidades básicas para o uso de computadores e da Internet." Uma das maneiras de enfrentamento dessa dificuldade pelos municípios estudados foi o oferecimento, formalizado ou não, de cursos e/ou guias de orientações sobre tecnologias e sobre as ferramentas utilizadas.

c. inconstância na participação e na entrega das atividades pedagógicas

A inconstância na participação e na entrega das atividades pedagógicas por parte dos alunos foi outro grande problema apontado pelos participantes. Os entrevistados que atuam na educação infantil foram os que mais sentiram essa inconstância. As maiores queixas giram em torno da falta de comprometimento das famílias, já que crianças pequenas necessitam que seus responsáveis organizem seus horários, espaços e materiais para a realização das atividades, e da falta de valorização da pré-escola e, principalmente, da creche no processo de escolarização da criança pequena.

Uma observação realizada por vários entrevistados, da educação infantil ao ensino fundamental, é referente ao desânimo que abateu as famílias no segundo semestre de 2020, quando se constatou que não haveria o retorno às aulas presenciais. Esse fato influenciou várias famílias a abandonar a entrega das atividades escolares.

Dois procedimentos utilizados para enfrentar essa dificuldade foram a entrega de atividades no domicílio e o uso da busca ativa dos alunos. Todos os municípios aplicaram este último artifício em conjunto com o Conselho Tutelar e outras Secretarias Municipais, como a de Saúde e a de Assistência Social.

Participante E - "[...] o diretor, ele tem a obrigação de fazer a busca ativa desse aluno. Então, tanto na retirada quanto na entrega. Então, por exemplo, se 10 alunos não foram retirar atividade, o gestor tem que fazer a busca ativa, e não é só ligar, tá. Aqui nós não consideramos ligação como busca ativa. Ele tem que fazer visita domiciliar, ele tem que mandar carta registrada, ele tem que ter documentação de que ele falou com esse pai, que ele orientou esse pai, para esse pai buscar [os materiais impressos]."

A busca ativa é um dos procedimentos indicados pela legislação nacional e estadual para lidar com a ausência e evasão dos alunos antes mesmo da pandemia. Na legislação 
paulista, a Resolução Seduc-48/2020 (SÃO PAULO, 2020a) foi a primeira a propor o procedimento para o monitoramento dos alunos em situação de risco de evasão e abandono escolar durante a Covid-19. Em consonância com essa Resolução, muitos municípios adotaram esse procedimento para assegurar que o ERE chegasse a todos os alunos de suas redes.

\section{3) Ações bem-sucedidas na implementação do ERE}

A terceira categoria de análise indica as ações bem-sucedidas alcançadas pela implementação do ERE pela percepção dos entrevistados desse estudo. Consideramos aqui ações bem-sucedidas aquelas cujo sucesso dependeram do exercício de planejamento do ERE ou do empreendimento das SME/DME e dos profissionais da educação na resolução de alguma dificuldade.

A seguir, por ordem de maior ocorrência, estão listadas essas ações.

a. superação das dificuldades com a tecnologia por parte dos docentes

A superação das dificuldades com a tecnologia por parte da equipe pedagógica e do corpo docente, ainda que parcial, foi um ponto positivo apontado por todos os participantes em algum momento da entrevista. Contudo, é importante sinalizar que essa superação não é dada, na nossa percepção das manifestações dos entrevistados, como uma ação concluída, mas como parte de um processo maior em andamento. Questões como a do domínio do comodismo, da resistência, do medo e da progressiva aquisição de habilidade para a utilização da tecnologia nas práticas pedagógicas são associadas à superação das dificuldades com a tecnologia pelos entrevistados.

Participante B - “[...] a nossa superação, éh, enquanto profissional, de ver essa possibilidade. Porque até então eu achava que a tecnologia tava longe de mim, ela não tá e eu tenho capacidade de usá-la também, mesmo com a dificuldade."

Para impulsionar a superação dessa dificuldade, todas os municípios ofereceram algum suporte de formação para a tecnologia, seja com cursos específicos, seja com orientações pontuais.

A maior parte dos entrevistados manifestou que a necessidade do uso da tecnologia durante 2020 fez com que o sistema municipal de ensino e os próprios funcionários procurassem por mais qualificação e formação para implementar o ERE, o que fomentou a superação dessa dificuldade. 
b. engajamento dos profissionais da educação

A preocupação dos profissionais da educação em prover uma educação de qualidade e o sucesso na implementação do ERE foi outra constante nas manifestações dos entrevistados. A maioria dos entrevistados enfatizou o engajamento dos profissionais da educação como um ponto positivo, já que a pandemia e a suspensão de aulas presenciais fizeram aflorar a união entre eles em prol de um bem comum, o atendimento às necessidades de aprendizagem dos alunos.

Participante $\boldsymbol{A}$ - "Num primeiro momento, nós pensamos também que muitos professores iriam ficar resistentes, né, porque quando se falava em tecnologia na escola, muitos professores [falam]: _. Ah, mas eu não sei montar as coisas no computador. [...] Então, nós achávamos que a resistência desses professores ia ser uma dificuldade muito grande pra nós e pelo contrário, [...]. E todos eles estão muito envolvidos nesse trabalho."

Esse engajamento dos professores, segundo os entrevistados, pode ser observado na busca por mais conhecimentos sobre o uso da tecnologia para a educação, na expressão do comprometimento para com o processo de ensino e aprendizagem dos alunos e na empatia com a situação destes durante a pandemia.

c. proximidade da escola com as famílias

A relação mais próxima entre escola e família foi outro ponto positivo ressaltado por vários dos entrevistados, muitos dos quais apontaram que ela é, em grande parte, resultado do diálogo bem-sucedido realizado via WhatsApp. Esse aplicativo de comunicação social, na visão de alguns dos entrevistados, trouxe a simultaneidade para as comunicações e uma via direta entre escola e família, antes realizada muitas vezes pelo precário intermédio de bilhetes.

Nas manifestações dos entrevistados, distinguimos outro fator que favoreceu essa relação de proximidade: a necessidade das famílias em participar mais ativamente das atividades escolares. Essa necessidade aparece principalmente na preocupação dos professores em buscar meios de fomentar a participação. Na visão de alguns entrevistados, esse processo acabou acarretando maior valorização da escola e do papel do professor no processo de ensino e aprendizagem das crianças.

Todos os entrevistados apontaram estes pontos positivos em comum: a superação das dificuldades com a tecnologia por parte dos professores, o engajamento dos profissionais da educação e a maior proximidade entre escola e família. 


\section{4) Inovações observadas com a implementação do ERE}

A quarta e última categoria de análise aponta o que, na visão dos participantes, pode ser vista como uma inovação para a educação, inclusive para o ensino pós-pandemia, conforme descrito na sequência.

a. uso da tecnologia para o ensino nos primeiros níveis da educação básica

Para os participantes da pesquisa, apesar de todos os sobressaltos desse período, é unânime os benefícios que o ERE trouxe no que se refere ao uso e às experiências de ensino e aprendizagem envolvendo a tecnologia para os primeiros níveis de ensino na educação básica, no que cabe aqui, educação infantil e anos iniciais do ensino fundamental. O que diverge, em alguns casos, é quanto ao público-alvo beneficiado, no caso, profissionais da educação e/ou alunos.

Para os professores, em termos de crescimento profissional e possibilidades de intervenção nas práticas pedagógicas, o uso da tecnologia foi visto pelos entrevistados como um fator de inovação, pois ela pouco se estendia para além da pesquisa de conteúdos e atividades para elaboração de aulas e das questões pedagógico-administrativas, como produção e envio de relatórios por meio de ferramentas básicas de edição de textos e correio eletrônico.

Com o ERE, os professores têm aprendido a lidar com a plataforma de ensino online e aplicativos de comunicação social voltada para grupos de trabalho, o que envolve postagens de materiais, orientações e devolutivas aos alunos, gravação de áudios e vídeos, gerenciamento de videoaulas, chats e similares etc. Além disso, têm participado de reuniões pedagógicas online, cursos de capacitação também online e aprendido a utilizar outras ferramentas que auxiliam seu trabalho de registro, avaliação e acompanhamento, como ferramentas de questionários online e de planilhas etc.

Participante C - "[...] tem que ver cada coisa bonitinha que agora, esse último mês, elas [as professoras] tinham mandado alguns exemplos pra gente, né, de atividade. Então, tinha videozinho que a professora, sabe, com a musiquinha, a própria professora da sala fez o videozinho, se fantasiou, então, eu acho que isso é, que foi o diferente. [...]."

No que tange aos alunos, um dos entrevistados coloca que, na sua percepção, os alunos da educação infantil perderam muito no processo, já que a base do currículo, segundo a Base Nacional Comum Curricular (BNCC) (BRASIL, 2017) é a interação entre pares e professores, que foi prejudicada durante a implantação do ERE. Já para os alunos maiores, 
alguns entrevistados apontaram a possibilidade de trabalhar com a autonomia e o protagonismo dos alunos, com atividades de pesquisas e de interação pedagógica, o que foi considerado um ponto positivo.

No geral, a tecnologia nas escolas tem sido pensada no sentido de consumo de informações, mas não de autoria ou produção, como nos aponta Tarouco (2018) num artigo sobre a competência digital dos professores. Para a autora, a fluência digital se desenvolve a partir de um processo de alfabetização digital, mas a ultrapassa, colocando o professor como um aprendiz, líder, cidadão, colaborador, designer, facilitador e analista, todas habilidades que envolvem não apenas a questão do consumo, mas da exploração e da integração, e nós diríamos ainda da interação, habilidades que devem ser trabalhadas e desenvolvidas nos alunos também.

Isso posto, o aumento no uso da tecnologia associado à implementação do ERE é uma questão positiva apontada como um ganho que a educação não pode deixar retroceder já que tem um alto potencial formativo para a emancipação e para o protagonismo tanto do professor quanto do aluno. Além disso, a tecnologia pode propiciar interatividade e dinamismo para os processos de escolarização, trazendo a educação pública mais próxima da cultura emergente, midiática e digital, do século XXI.

\section{b. interação virtual}

Outra inovação destacada entre os participantes é a interação virtual entre família e escola e entre equipe gestora e professores. Essa interação revelou o entusiasmo encontrado pelos profissionais da educação na maior proximidade que o ERE proporcionou por meio das ferramentas de comunicação, como aplicativos de celulares, mídias sociais digitais e aplicativos de reuniões online.

No que diz respeito à comunicação entre escola e família, que antes era realizada por meio de telefonemas e bilhetes, passa a ser mais direta, estável e imediata, garantindo que a mensagem chegue ao seu destinatário com maior segurança e rapidez. No geral, os participantes desse estudo destacaram esse como um dos pontos mais importantes, pois gerou não só maior comunicação como maior proximidade em termos de relacionamento, motivando a parceria da escola com a comunidade. Esse fator também é considerado uma ação bem-sucedida.

Participante D - "No início teve escola que falou que não ia fazer grupo pelo WhatsApp, que ia tentar pelo telefone da escola fazer esse contato. Não deu certo. [...] Não conseguiram outro caminho, então, eles, eles aderiram ao WhatsApp mesmo." 
No tocante aos profissionais da educação, a interação virtual, por meio das ferramentas de tecnologia, proporciono maior engajamento entre equipes gestoras e professores. Parte dessa percepção vem da relação mais direta e imediata que essas ferramentas proporcionam, como a maior proximidade virtual sincrônica que vem ocorrendo entre profissionais das SME/DME e das escolas. A realização do Horário de Trabalho Pedagógico Coletivo (HTPC) online foi citada por alguns dos entrevistados como um ganho na relação gestão versus escola, sendo um dos pontos discutidos para permanência pós-pandemia.

De modo geral, todos os municípios utilizaram algum tipo de aplicativo para reuniões online e fizeram uso do WhatsApp para a comunicação com as famílias e com os profissionais da educação.

\section{c. formação online}

A formação e a capacitação para o uso da tecnologia ou o uso da tecnologia para a formação e a capacitação também são citadas pelos participantes como algo que deve ser mantido. Embora não seja considerada uma inovação em si, a capacitação ou formação online ainda não estava disseminada nas redes de ensino antes da pandemia. A maior parte dos cursos até então eram presenciais, acarretando inclusive grandes deslocamentos de pessoal e recursos. A exemplo disso, todos os entrevistados apontaram que as formações das redes municipais sempre foram presenciais e a oferta de formações online pouco acolhidas.

Participante $\boldsymbol{H}$ - "Eles [o sistema de ensino conveniado] tão se reorganizando, eles já tinham inclusive, viu, algumas aulas online, mas ninguém utilizava, entendeu. Então, agora, as pessoas estão buscando mais isso, né. Então, essa busca pelo novo. Eu acho que pós-pandemia isso vai continuar."

Entre as inovações apontadas pelos entrevistados, o uso da tecnologia para um ensino híbrido, a interação virtual e a formação online, observamos que todas já estão presentes na sociedade digital que nós temos hoje e em muitos sistemas de educação, como no educação superior, contudo, elas pouco tinham adentrado à escola básica pública antes da pandemia, o que as fez serem reconhecidas como uma novidade.

Assim, o desenvolvimento de uma educação para a tecnologia nos anos iniciais do ensino fundamental e na educação infantil, que vise professores e alunos protagonistas, implica "inovações" levantadas nesse estudo e outras que possam trazer a tecnologia para a escola de maneira a potencializar o processo de escolarização. 


\section{Considerações finais}

Esse estudo teve como objetivo compreender como o ERE foi pensado nas redes municipais de ensino de uma microrregião do interior paulista, situada na mesorregião de Campinas. O propósito desse artigo assenta-se em uma análise descritiva das principais características que envolveram o planejamento e a implementação do ERE nessa microrregião, identificando e descrevendo as estratégias de ensino, as dificuldades, as ações bem-sucedidas e as inovações mais recorrentes a partir do cenário que ora se apresenta em decorrência da pandemia da Covida-19 nos anos de 2020 e 2021.

Iniciando pelas características principais desse processo, percebemos algumas confluências entre os municípios dessa localidade, mesmo seu planejamento sendo realizado segundo as especificidades de cada público-alvo. Alguns dos fatores que influenciam essa confluência, de acordo com nossa percepção das manifestações dos participantes, são o porte dos municípios, o acesso à tecnologia e as redes de apoio à informação.

Os municípios de grande porte seguiram propostas similares para o planejamento do ERE, como o uso de plataforma de ensino online e a centralização do planejamento inicial nas SME. Já os municípios de pequeno porte optaram por um planejamento mais descentralizado, englobando escolas e professores, além do uso de ferramentas tecnológicas conhecidas pela comunidade escolar como estratégia principal para a implementação do ERE, como o WhatsApp, no caso do município de pequeno porte I, e a distribuição de materiais impressos, no caso do de pequeno porte II.

Em redes de ensino maiores, as dimensões podem ser consideradas um fator complicador na estruturação do ERE, já que quanto maior o número de escolas, professores e alunos, maior a dificuldade de organização, orientação e monitoramento das atividades, ou seja, maior o grau de complexidade do sistema educacional, o que, de certa forma, pode ter motivado o planejamento inicial mais centralizado.

No que concerne à tecnologia, entendemos que a falta de acesso à tecnologia, principalmente à internet, acabou por influenciar a maneira como o ERE foi planejado e implementado nos diferentes municípios da microrregião. Os municípios de pequeno porte e/ou com população rural maior e menos recursos tecnológicos optaram pela não utilização de plataformas de ensino online, enquanto para os municípios de grande porte, essa foi uma solução inicial para abranger a rede toda. 
Segundo Malganova, Dokhkilgov e Saralinova (2021, p. 603), “deve-se entender a diferença na prontidão da população de grandes cidades com infraestrutura bem desenvolvida, que é muito mais fácil de se adaptar ao mudar para online do que usuários de áreas rurais."

Quanto às redes de apoio consultadas para obtenção de informações e orientações para o planejamento do ERE, as mais citadas foram a UNDIME, a DE/SEE e SME/DME de outras regiões. A busca por informações em redes comuns, por propiciar a troca de conhecimento sobre as mesmas experiências e orientações, pode gerar similaridades na seleção de estratégias de ensino, por exemplo, entre outras questões.

Entre as estratégias de ensino mais adotadas pelos municípios participantes desta pesquisa para a implementação do ERE estão a distribuição de materiais impressos, utilizadas por todos os municípios por seu poder inclusivo, já que atende alunos com e sem acesso à tecnologia, o uso de plataforma de ensino online, utilizada pelos municípios de grande porte, e a criação de salas de aula no WhatsApp e no WhatsApp Business. Como já discutido, essas estratégias foram selecionadas sob a influência da realidade do acesso à tecnologia pelos alunos em cada município.

A segunda categoria de análise desse estudo é definida como "dificuldades enfrentadas". Embora haja dificuldades específicas em cada município, levantamos as mais recorrentes nessa microrregião, de acordo com as manifestações dos entrevistados. São elas: a falta de acesso de alunos e professores aos recursos tecnológicos, a falta de fluência digital por dos professores e a inconstância na participação e na entrega das atividades pelos alunos. As duas primeiras dificuldades levantadas se remetem à tecnologia e foram sentidas tanto nos municípios que adotaram ferramentas de TIC e TDIC para a implementação do ERE, quanto pelo que não adotou, caso do município de pequeno porte II, já que a própria decisão da não adoção destas foi levada em conta pela falta de acesso à tecnologia e fluência digital por sua comunidade escolar.

A terceira e quarta e quinta categorias são, respectivamente, ações bem-sucedidas e inovações. Entre as ações bem-sucedidas mais recorrentes identificamos a superação das dificuldades com a tecnologia por parte da equipe pedagógica e docente, o engajamento e comprometimento dos profissionais da educação e a proximidade da escola com as famílias. Entre as inovações, o uso da tecnologia para um ensino nos primeiros níveis da educação básica, a interação virtual e a formação online.

No que corresponde às ações bem-sucedidas, observamos uma interrelação entre elas. A superação das dificuldades com a tecnologia é resultado do comprometimento dos professores e profissionais da educação com a implementação do ERE. O engajamento dos 
profissionais da educação e dos professores também fomentou uma maior proximidade entre escola/docente e família/aluno. Essa interrelação nos leva a inferir que o "engajamento", seja um dos fatores determinantes para o desenvolvimento das outras duas ações consideradas bem-sucedidas. Sem o desenvolvimento dessa ação, a promoção das outras estaria provavelmente comprometida.

As inovações observadas durante a implementação do ERE nesses municípios não são ações novas na sociedade, mas, por entrarem na educação básica pública nesse contexto, foram consideradas como uma ação transformadora que pode produzir uma renovação para a educação se se mantiverem e forem bem utilizadas no período pós-pandemia. Surge, em muitas das manifestações dos entrevistados, o desejo de que algum tipo de ensino híbrido ou integrado às tecnologias se faça realidade neste porvir, acelerando e concretizando o que se tem ensaiado ao longo de todo este início de século sem muito sucesso no que diz respeito a uma educação básica integrada à tecnologia.

Reconhecemos que, mesmo com os avanços tecnológicos obtidos com o ERE, ele não é uma solução unânime e nem a mais apropriada para o ensino de crianças pequenas e préadolescentes, deixando muitas lacunas e desigualdades ao longo do caminho. No entanto, resgatando o posicionamento da ONG Todos pela Educação (2020), o ERE é uma opção à opção de não se fazer nada. Mesmo com muitos problemas e questões importantes a serem discutidas durante sua implementação, na voz dos entrevistados dessa pesquisa, a intenção do ERE é de fazer com que o processo de escolarização não seja interrompido.

Em geral, o ensino a distância por si só não é uma solução de longo prazo. A crise do COVID-19 lança luz sobre a necessidade de um novo modelo de educação. Em breve teremos uma experiência de aprendizagem mista, uma espécie de refúgio educacional híbrido, imaginado na combinação do melhor dos dois formatos de aprendizagem (MALGANOVA; DOKHKILGOV; SARALINOVA, 2021, p. 603).

Essa pesquisa se mostra relevante pela importância que assumem as investigações e os registros sobre a experimentação do ERE em larga escala pelas SME/DME durante a pandemia da Covid-19. Essa situação trouxe uma conjuntura de excepcionalidade à educação, que exigiu ações originais e singulares, mas que impôs uma série de problemas e lacunas a serem (re)pensadas nos próximos anos, entre estas, a emergência de uma grande população invisível dentro do sistema de escolarização, que não conseguiu acesso à educação e/ou fícou excluída desse processo.

Nesse contexto, faz-se urgente pensar a educação do pós-pandemia utilizando todos os recursos necessários para o suprimento das lacunas que surgiram e resgatando a população 
excluída desse processo. E as experiências vivenciadas com o ERE, que, de alguma forma, trouxe certa integração entre as tecnologias e as práticas escolares, pode ser uma aliada nesse novo cenário.

AGRADECIMENTOS: O presente trabalho foi realizado com apoio da Coordenação de Aperfeiçoamento de Pessoal de Nível Superior Brasil (CAPES) - Código de Financiamento 001 .

\section{REFERÊNCIAS}

BARDIN, L. Análise de Conteúdo. São Paulo: Martins Fontes, 2016.

BRASIL. Constituição da República Federativa do Brasil de 1988. Brasília, 1988. Disponível em: http://www.planalto.gov.br/ccivil 03/constituicao/constituicao.htm. Acesso em: 17 dez. 2020.

BRASIL. Decreto n. 9.057, de 25 de maio de 2017. Regulamenta o art. 80 da Lei no 9.394, de 20 de dezembro de 1996, que estabelece as diretrizes e bases da educação nacional. Brasília, 2017. Disponível em: http://www.planalto.gov.br/ccivil_03/Ato20152018/2017/Decreto/D9057.htm. Acesso em: 17 dez. 2020.

BRASIL. Lei n. 14.040, de 18 de agosto de 2020. Estabelece normas educacionais excepcionais a serem adotadas durante o estado de calamidade pública reconhecido pelo Decreto Legislativo $\mathrm{n}^{\mathrm{o}}$ 6, de 20 de março de 2020; e altera a Lei ${ }^{\circ} 11.947$, de 16 de junho de 2009. Brasília, 2020. Disponível em: http://www.planalto.gov.br/ccivil_03/ato2019_ 2022/2020/lei/L14040.htm. Acesso em: 17 dez. 2020.

BRASIL. Lei n. 9.394, de 20 de dezembro de 1996. Estabelece as diretrizes e bases da educação nacional. Brasília, 1996. Disponível em:

http://www.planalto.gov.br/ccivil_03/leis/19394.htm. Acesso em: 17 dez. 2020.

BRASIL. Ministério do Desenvolvimento Social e Combate à Fome. Secretaria Nacional de Assistência Social. Política Nacional de Assistência Social (PNAS) (2004): Norma Operacional Básica NOB/SUA. Brasília: Ministério do Desenvolvimento Social e Combate à Fome Secretaria Nacional de Assistência Social, 2005.

CIEB. Centro de Inovação para Educação Brasileira. Planejamento das Secretarias de Educação do Brasil para Ensino Remoto. 2020. Disponível em: https://cieb.net.br/wpcontent/uploads/2020/04/CIEB-Planejamento-Secretarias-de-Educac\%C3\%A3o-para-EnsinoRemoto-030420.pdf. Acesso em: 10 mar. 2020.

CRAIG, $R$. What students are doing is remote learning, not online learning. There's a Difference. Opinion - EdSurge, 2020. 
GARCIA, T. C. M. et al. Ensino remoto emergencial: orientações básicas para elaboração do plano de aula [recurso eletrônico]. Natal, PA: SEDIS/UFRN, 2020.

IBGE. Instituto Brasileiro de Geografia e Estatística. Censo Demográfico - 2010:

Características da população e dos domicílios. Resultados do universo. Rio de Janeiro: IBGE, 2011.

IBGE. Instituto Brasileiro de Geografia e Estatística. Cidades@. Disponível em: https://cidades.ibge.gov.br/brasil/sp/panorama. Acesso em: 19 jul. 2021.

IBGE. Instituto Brasileiro de Geografia e Estatística. Divisão Regional do Brasil em Regiões Geográficas Imediatas e Regiões Geográficas Intermediárias. Rio de Janeiro: IBGE, 2017. Disponível em: https://www.ibge.gov.br/apps/regioes_geograficas/. Acesso em: 19 jul. 2021.

INEP. Instituto Nacional de Estudos e Pesquisas Educacionais Anísio Teixeira. Índice de Desenvolvimento da Educação Básica (IDEB). Disponível em:

http://ideb.inep.gov.br/resultado/home.seam?cid=30206. Acesso em: 20 jul. 2021.

MACHADO, D G., CZARNESK, F. R.; DOMINGUES, M. J. C. S. Perfil das metodologias de ensino presencial e a distância na graduação em administração. Estudo \& Debate, Lajeado, v. 22, n. 2, p. 105-122, 2015.

MALGANOVA, I. G.; DOKHKILGOVA, D. M.; SARALINOVA, D. S. A transformação do sistema educacional durante e pós-COVID-19. Revista on line de Política e Gestão Educacional, Araraquara, v. 25, n. esp. 1, p. 595-605, mar. 2021. e-ISSN:1519-9029. DOI: https://doi.org/10.22633/rpge.v25iesp.1.14999

NICOLA, J. F; PALARO, S. M. C.; LEMES, S. S. Ser professor ou estar professor: as implicações no contexto de sala de aula. Revista on line de Política e Gestão Educacional, Araraquara, v. 25, n. 1, p. 344-366, jan./abr. 2021. e-ISSN:1519-9029. DOI:

https://doi.org/10.22633/rpge.v25i1.14937

ONG Todos pela Educação. Educação na pandemia: ensino a distância dá importante solução emergencial, mas resposta à altura exige plano para volta às aulas. Disponível em: https://www.todospelaeducacao.org.br/conteudo/Educacao-na-pandemia-Ensino-a-distanciadaimportante-solucao-emergencial_-mas-resposta-a-altura-exige-plano-para-volta-as-aulas. Acesso em:15/01/2021.

SÃO PAULO. Resolução Seduc-48, de 29 de abril de 2020. Define, no âmbito da Secretaria da Educação, as atividades de natureza essencial e dá providências correlatas. $2020^{\mathrm{a}}$.

Disponível em:

http://www.educacao.sp.gov.br/lise/sislegis/detresol.asp?strAto=202004290048. Acesso em: 27 maio 2021.

SÃO PAULO. Resolução Seduc-46, de 24 de abril de 2020. Estabelece o protocolo de entrega de materiais pedagógicos aos alunos matriculados na rede pública estadual de ensino. 2020b. Disponível em:

http://www.educacao.sp.gov.br/lise/sislegis/detresol.asp?strAto=202004240046. Acesso em: 20 jul. 2021. 
SÃO PAULO. Resolução Seduc-45, de 20 de abril de 2020. Dispõe sobre a realização e o registro de atividades escolares não presenciais pelas unidades escolares vinculadas ao Sistema de Ensino do Estado de São Paulo, durante o período de restrição das atividades presenciais devido à pandemia de COVID19. 2020c. Disponível em:

http://www.educacao.sp.gov.br/lise/sislegis/detresol.asp?strAto=202004204500. Acesso em: 20 jul. 2021.

SÃO PAULO. Resolução Seduc-28, de 19 de março de 2020. Dispõe sobre medidas temporárias de prevenção ao contágio e à transmissão do Covid-19(Novo Coronavírus) no âmbito da Secretaria da Educação, em complementação àquelas previstas no Decreto 64.864/2020. 2020d. Disponível em:

http://www.educacao.sp.gov.br/lise/sislegis/detresol.asp?strAto=202003190028. Acesso em: 20 jul. 2021.

SÃO PAULO. Deliberação Conselho Estadual de Educação n 177 , de 18 de março de 2020. Fixa normas quanto à reorganização dos calendários escolares, devido ao surto global do Coronavírus, para o Sistema de Ensino do Estado de São Paulo, e dá outras providências. 2020e. Disponível em:

https://www.ime.unicamp.br/sites/default/files/inline/349/deliberacao_cee_177_20_-_covid19.pdf.pdf. Acesso em: 20 jul. 2021.

TAROUCO, L. M. R. Competências Digitais dos Professores. In: Comitê gestor da internet no brasil. Pesquisa sobre o uso das tecnologias de informação e comunicação nas escolas brasileiras: TIC Educação 2018. São Paulo: Comitê Gestor da Internet no Brasil, 2019.

UNDIME. Sobre a UNDIME. Disponível em: http://www.undime-sp.org.br/historia/. Acesso em: 27 maio 2021.

\section{Como referenciar este artigo}

TEBALDI, E. L. P. R.; LEMES, S. S. Análise do ensino remoto emergencial numa microrregião do interior paulista. Revista on line de Política e Gestão Educacional, Araraquara, v. 25, n. 3, p. 2861-2885, set./dez. 2021. e-ISSN:1519-9029. DOI: https://doi.org/10.22633/rpge.v25i3.15361

Submetido em: $11 / 08 / 2021$

Revisões requeridas em: 10/09/2021

Aprovado em: $15 / 10 / 2021$

Publicado em: 08/12/2021 